\title{
Cardiovascular Risk Burden in Sub-Saharan Africans with Rheumatoid Arthritis: A Hospital-Based Study in Yaounde, Cameroon
}

\author{
Madeleine Singwe-Ngandeu, ${ }^{1,2}$, Mickael Essouma1, Vicky Jocelyne Ama Moor ${ }^{1,3}$, \\ Ahmadou Jingi Musa', Alain Patrick Menanga ${ }^{1,4}$, Caroline Ngoufack ${ }^{2}$, Sandrine Sa'a Lontsi' \\ Thierry Ntandzi ${ }^{2}$, Yolande Vanessa Ayi Efoua ${ }^{2}$, Mireille Cathy Melong Pianta ${ }^{1}$ \\ ${ }^{1}$ Faculty of Medicine and Biomedical Sciences, The University of Yaoundé I, Yaounde, Cameroon \\ ${ }^{2}$ Rheumatology Unit, Yaounde Central Hospital, Yaounde, Cameroon \\ ${ }^{3}$ Biochemistry Laboratory, Yaounde University Teaching Hospital, Yaounde, Cameroun \\ ${ }^{4}$ Cardiology Unit, Yaounde General Hospital, Yaounde, Cameroon \\ Email: ngandeum@yahoo.fr
}

Received 15 September 2015; accepted 13 February 2016; published 16 February 2016

Copyright (C) 2016 by authors and Scientific Research Publishing Inc.

This work is licensed under the Creative Commons Attribution International License (CC BY). http://creativecommons.org/licenses/by/4.0/

c) (i) Open Access

\section{Abstract}

Introduction: Studies on RA (rheumatoid arthritis) and cardiovascular risk in African countries are scarce. Objective: To investigate the relationship between RA and cardiovascular risk in Cameroonian patients. Methodology: In 50 Black RA patients and 51 matched healthy individuals from the general population, we studied cardiovascular risk factors validated by the WHO. Cardiovascular risks estimates were carried out using WHO risk charts for the African region. Epi-info, $R$ and SPPS were used for the statistical analysis. Results: Overall and abdominal adiposity as expressed by increased body mass index and abdominal obesity, were all markedly increased in RA patients compared to non-RA subjects $[70 \%$ vs. $47 \%, 0 R(95 \% \mathrm{CI})=2.62(1.16-5.94), p=0.026$; and $54 \%$ vs. $33 \%, 0 R(95 \% \mathrm{CI})=2.34(1.05-5.25), \mathrm{p}=0.045$ respectively]. RA patients were more physically inactive than their non-RA counterparts $(20 \%$ vs. $0, p=0.001)$. Whereas $R A$ was associated with a reduced odds of alcoholism $[\mathrm{OR}(95 \% \mathrm{CI})=0.19(0.06-0.62), \mathrm{p}=0.005]$. Increased BMI seemed to occur independently of methotrexate $(p=0.76)$, hydroxychloroquine $(p=0.59)$, corticosteroids $(p=0.79)$ treatments, and independently of $\operatorname{sex}(p=0.15)$, age $(p=0.67)$, and sedentary lifestyle ( $p=0.16$ ) in RA patients; but their BMI was weakly correlated with disease duration $(r=0.26 ; p=0.074)$. Meanwhile, male gender was associated with a reduced odds of abdominal obesity [OR $(95 \% \mathrm{CI})=0.02(0-0.4), \mathrm{p}=0.011]$. Cardiovascular risk, comparable by proportions between RA and non-RA subjects, was low in 26 patients $(78.8 \%)$ and 30 non-RA subjects $(83.3 \%)$ respectively. Conclusion: Despite the high adiposity burden and a sedentary lifestyle experienced by RA patients compared to their healthy counterparts, RA was not associated with cardiovascular risk as estimated by WHO risk charts.

How to cite this paper: Singwe-Ngandeu, M., Essouma, M., Moor, V.J.A., Musa, A.J., Menanga, A.P., Ngoufack, C., Lontsi, S.S., Ntandzi, T., Efoua, Y.V.A. and Pianta, M.C.M. (2016) Cardiovascular Risk Burden in Sub-Saharan Africans with Rheumatoid Arthritis: A Hospital-Based Study in Yaounde, Cameroon. Open Journal of Rheumatology and Autoimmune Diseases, 6, 1-9. http://dx.doi.org/10.4236/ojra.2016.61001 


\section{Keywords}

\section{Rheumatoid Arthritis, Excess Adiposity, Physical Inactivity, Cardiovascular Risk, World Health Organization Risk Charts}

\section{Introduction}

Rheumatoid Arthritis (RA) is a disabling systemic autoimmune disease that affects $0.24 \%$ of the world's population. The prevalence is estimated to be around $0.42 \%$ in Africa [1] [2]. The advent of effective immunomodulator treatments has reduced mortality in these patients in the past decade [3] [4]. However, mortality attributed to RA remains high compared to the general population [3]. This is closely related with the presence of comorbidities such as: infections, cancers, osteoporosis, and cardiovascular diseases (CVD) [4]. RA is increasingly being reported as an independent cardiovascular risk factor in temperate regions [5]-[11]. The reasons for implemented cardiovascular risk in RA patients are postulated to be linked with both traditional risk factors and chronic inflammation, and potentially to medications including non-steroidal anti-inflammatory drugs, corticosteroids and disease-modifying antirheumatic drugs [12]-[14]. Among traditional cardiovascular risk factors, hypertension, type 2 diabetes mellitus, dyslipidemia, smoking and obesity appear to significantly impact on the cardiovascular disease (CVD) burden in RA [12] [13]. Most importantly, chronic inflammation and immune activation (expressed by high serologic inflammatory biomarkers e.g. C-reactive protein) are crucial for the occurrence and worsening of CVD in the RA population [15]. Although $~ 80 \%$ of CVD now occurs in low- and middle-income countries including Sub-Saharan Africa, there are astonishingly few reports addressing the relationship between CVD and RA which remains debatable with potentially different predictors in Black Africans as compared to western population. Notably, Kirui et al. found hypertension as the only cardiovascular risk factor associated with RA in a Kenyan cross-sectional comparative study [16]. Similarly, a recent review summarizing evidence from South African Black RA patients reported no association between traditional risk factors and RA, despite an overall increased atherosclerotic burden [17]. Furthermore, adipokines and reduced kidney function were demonstrated to be associated with atherosclerosis in Black south African RA population, whereas, traditional risk factors were the main determinants for CVD in the White RA patients [17] [18]. Taken collectively, studies are still largely warranted to precise the putative link between CVD and RA across Sub-Saharan African countries. This work aimed to study the relationship between cardiovascular risks and RA in Cameroonian patients using the World Health Organization (WHO) and International Society for Hypertension (ISH) risk charts.

\section{Methodology}

This was a cross sectional comparative study. RA patients aged 18 years and above, followed up in the rheumatology unit of the Yaounde Central Hospital between January 2004 and December 2014, and who gave informed consent to participate in the study were recruited from December 2013 to April 2014. The diagnosis of RA was based on ACR and/or ACR/EULAR diagnostic criteria [19] [20]. We excluded patients with mixed connective tissue disease, Human Immunodeficiency Virusinfection, hereditary dyslipidemia, chronic kidney disease, and any other active chronic inflammatory disease. Non-RA subjects were clinically healthy volunteers recruited from the community at the same time as the non-RA subjects. They were matched for sex, age, and race. Pregnant women were excluded from both groups. As it was a preliminary study, a convenient non probabilistic sampling was used. Demographic, clinical, and biological data were obtained on the same visit, during which each participant underwent a complete clinical examination (history and physical examination), and blood drawn after a fast of at least 12 hours. Blood pressure was measured with a clinically validated electronic device (Magnien B1) [21], with the cuff applied to the mid left arm, in the sitting position, after at least five minutes of rest, and no tobacco use prior to the measurements. The average of at least two blood pressure measurements was recorded. Hypertension was defined by as a systolic blood pressure $\geq 140$ and/or a diastolic blood pressure $\geq 90 \mathrm{mmHg}$ [22]. Body weight (kg), was measured with a mechanical scale balance (precision $\pm 0.5 \mathrm{~kg}$ ) in participants barefoot, and lightly dressed. Height (m) was measured with a locally made stadiometer. Body Mass Index (BMI) was calculated using Quetelet's indices and excess adiposity was defined by BMI $\geq 25 \mathrm{~kg} / \mathrm{m}^{2}$ [23]. Waist circumference was measured with a meter tape midway between the lower border of the twelfth rib and 
the antero-superior iliac spine. Abdominal obesity was defined as waist circumference $\geq 102 \mathrm{~cm}$ in men, and $\geq$ $88 \mathrm{~cm}$ in women [23]. Blood was drawn by venous puncture in the forearm crease after strict asepsis. Seven milliliters of this was collected in a dry tube and three milliliters in a fluorinated tube for each participant. The tubes were immediately sent to the biochemistry laboratory of the Yaounde University Teaching Hospital, and analyzed the same day for blood glucose, serum cholesterol, and uric acid.

Cardiovascular risk factors studied were those described in the literature and validated by the WHO [22]-[25]. Cardiovascular risks estimates were carried obtained from WHO/ISH charts appropriate for the Cameroonian general population [24]. These charts provide an estimate of the individual risk of cardiovascular events for the upcoming 10 years stratifying by diabetic/non Diabetic status. Further elements considered when assessing the cardiovascular risk with these charts are the sex, age (49 - 79 years) tobacco smoking status, as well as systolic blood pressure and blood cholesterol values. Accordingly, each subject fits into one of the five risk categories: low ( $<10 \%)$, moderate ( $10 \%$ to $<20 \%$ ), medium ( $20 \%$ to $<30 \%$ ), high ( $30 \%$ to $40 \%)$ and very high $(\geq 40 \%)$ [24].

Statistical softwares used were; Epi-info version 7, SPSS version 18, and R version 3.0.1. Quantitative variables were studied using Student $t$ test, and qualitative variables using chi square test and Fischer exact test when appropriate for the circumstances. Binary logistic regression was used to assess the main cardiovascular risk factors, with candidate predictors being: methotrexate, corticosteroids, hydroxychloroquine, male sex, advanced age ( $\geq 55$ years in men, and $\geq 65$ years in women), and sedentarity. A p-value $<0.05$ was considered statistically significant.

Authorizations to recruit participants and manipulate blood samples were obtained from the hospital administrations of the Yaounde Central and University Teaching Hospitals respectively. Ethical clearance was obtained from the Institutional Committee of the Faculty of Medicine and Biomedical Sciences of the University of Yaounde I. Signed informed consent was obtained for each participant in accordance with the Helsinki declarations.

\section{Results}

In all, 50 RA patients and 51 non-RA subjects were studied. The mean age was $51 \pm 14.8$ years for RA patients and $51.2 \pm 15.3$ years for non-RA subjects, $\mathrm{p}=0.916$. Their clinical characteristics are shown in Table 1 .

Amongst the cardiovascular risk factors noted (Table 2), clinical markers of adiposity including BMI $\geq 25$ $\mathrm{kg} / \mathrm{m}^{2}$ and abdominal obesity were respectively seen in $70 \%$ of RA patients and $47 \%$ of non-RA subjects [OR (95\% CI): 2.62 (1.16 - 5.94)], and 54\% of RA patients and 33\% of non-RA subjects [OR (95\% CI): 2.34 (1.05 5.25)]. Binary logistic regression analysis showed that high BMI was independent to age $(p=0.67)$, sex $(p=$ $0.15)$, sedentarity $(p=0.16)$ and use of methotrexate $(p=0.76)$, hydroxychloroquine $(p=0.59)$, and corticosteroids $(\mathrm{p}=0.79)$ treatments in RA patients (Table 3). Still, a correlation was observed between high BMI and duration of the disease in these patients $(r=0.26 ; p=0.074)$. Furthermore, male sex was not associated with risk of abdominal obesity $(\mathrm{p}=0.011)$ in RA-patients (Table 4).

Estimation of the cardiovascular risk using the WHO/ISH risk charts was possible in 33 RA patients and 36 non-RA subjects of both sexes aged between 40 - 79 years considering their diabetic/non diabetic status, their tobacco smoking status and their systolic blood pressure and blood cholesterol level. The 10-year risk was low in 26 RA patients (78.8\%) and in 30 non-RA subjects (83.3\%), moderate in three RA patients (9.1\%) and three non-RA subjects (8.3\%). High risk was noted in two RA patients (6.1\%) and one non-RA patient (2.8\%). Very high risk was seen in one RA patient (3\%) and one non-RA subject (2.8\%) (Figure 1). Rheumatoid arthritis was not associated with the cardiovascular risk.

\section{Discussion}

We studied the prevalence of traditional cardiovascular risk factors and assessed the cardiovascular risks in patients with RA, age and sex matched to non-RA subjects in a sub-Saharan urban central African setting. The results showed that markers of adiposity including BMI $\geq 25 \mathrm{~kg} / \mathrm{m}^{2}(\mathrm{p}=0.026)$ and abdominal obesity $(\mathrm{p}=0.045)$ were more frequent in RA patients. Lombard et al. in a descriptive study reported the same findings involving heterogeneous population with RA [26]. This contrasted with that reported by Dessein et al. [27], in a black population in South Africa. This controversy could be explained by different characteristics of non-RA population. High cardiovascular risk participants were included in their non-RA group. More so, non-RA subjects had significantly higher markers of inflammation than their RA counterparts. These inflammatory markers can promote 
Table 1. Demographic and clinical characteristics of the study population.

\begin{tabular}{|c|c|c|c|}
\hline \multirow{2}{*}{ Characteristics } & \multicolumn{2}{|c|}{ Rheumatoid arthritis } & \multirow[t]{2}{*}{ p-value } \\
\hline & Present & Absent & \\
\hline Age (mean \pm SD), Years & $51.0 \pm 14.8$ & $51.2 \pm 15.3$ & 0.916 \\
\hline \multicolumn{4}{|l|}{ Sex } \\
\hline -Females N (\%) & $39(78)$ & 39 (76.5) & 0.855 \\
\hline -Males N (\%) & $11(22)$ & $12(23.5)$ & \\
\hline Duration* (mean \pm SD), Years & $9.84 \pm 7.97$ & NA & \\
\hline Comorbidity, N (\%) & $34(68)$ & NA & \\
\hline -Infections & $29(58)$ & & \\
\hline -PUD & $16(32)$ & & \\
\hline -Osteoarthris & $1(2)$ & & \\
\hline -Asthma & $1(2)$ & & \\
\hline -Cancer & $1(2)$ & & \\
\hline -Depression & $1(2)$ & & \\
\hline -Parkinson's disease & $1(2)$ & & \\
\hline Treatment of RA, N (\%) & & NA & \\
\hline \multicolumn{4}{|l|}{-Symptomatic treatment } \\
\hline Corticosteroids & $26(52)$ & & \\
\hline NSAIDs & $2(4)$ & & \\
\hline \multicolumn{4}{|l|}{-Specific treatment } \\
\hline MTX & $24(48)$ & & \\
\hline HCQ & $5(10)$ & & \\
\hline AZT & $2(4)$ & & \\
\hline SSZ & $1(2)$ & & \\
\hline LEF & $1(2)$ & & \\
\hline -Without treatment & $18(36)$ & & \\
\hline
\end{tabular}

SD: Standard Deviation; Duration*: Duration of evolution of disease; N: Number; PUD: Peptic Ulcer Disease; RA: Rheumatoid Arthritis; NSAIDs: Non-Steroidal Anti-Inflammatory Drugs; MTX: Methotrexate; HCQ: Hydroxychloroquine; AZT: Azathioprine; SSZ: Sulfasalazine; LEF: Leflunomide; NA: Not Applicable.

Table 2. Prevalence of cardiovascular risk factors in the study population.

\begin{tabular}{|c|c|c|c|c|c|c|c|}
\hline \multirow[t]{3}{*}{ Variables } & \multicolumn{4}{|c|}{ Rheumatoid arthritis } & \multirow[t]{3}{*}{ OR } & \multirow[t]{3}{*}{$95 \% \mathrm{CI}$} & \multirow[t]{3}{*}{ p-value } \\
\hline & \multicolumn{2}{|c|}{ Present } & \multicolumn{2}{|c|}{ Absent } & & & \\
\hline & $\mathrm{N}$ & $(\%)$ & $\mathrm{N}$ & (\%) & & & \\
\hline $\mathrm{BMI} \geq 25 \mathrm{~kg} / \mathrm{m}^{2}$ & 35 & 70 & 24 & 47 & 2.62 & $1.16-5.94$ & 0.026 \\
\hline Abdominal obesity & 27 & 54 & 17 & 33 & 2.34 & $1.04-5.25$ & 0.045 \\
\hline Hypertension & 18 & 36 & 11 & 22 & 2.04 & $0.85-4.94$ & 0.13 \\
\hline Hyperuricemia & 8 & 16 & 5 & 10 & 1.75 & $0.53-5.78$ & 0.39 \\
\hline Menopause & 23 & 58 & 24 & 62 & 0.89 & $0.36-2.23$ & 1.00 \\
\hline Metabolic syndrome & 3 & 6 & 4 & 8 & 0.75 & $0.16-3.53$ & 1.00 \\
\hline Dyslipidemia & 25 & 50 & 30 & 59 & 0.7 & $0.32-1.54$ & 0.43 \\
\hline Alcohol misuse & 4 & 8 & 16 & 31 & 0.19 & $0.06-0.62$ & 0.005 \\
\hline Tobacco use & 1 & 2 & 7 & 14 & 0.13 & $0.01-1.08$ & 0.059 \\
\hline Sedentarity & 10 & 20 & - & - & $\mathrm{NC}$ & $\mathrm{NC}$ & 0.001 \\
\hline Diabetes & 5 & 10 & - & - & NC NC & $\mathrm{NC}$ & 0.056 \\
\hline CVA/TIA & 3 & 6 & - & - & $\mathrm{NC}$ & $\mathrm{NC}$ & 0.12 \\
\hline Ischemic Heart Disease & 1 & 2 & - & - & & NC & 0.49 \\
\hline
\end{tabular}

N: Number; OR: Odds Ratio; 95\% CI: 95\% Confidence Interval; BMI: Body Mass Index; WC: Waist Circumference; HC: Hip Circumference; HTN: Arterial Hypertension; NC: Not Calculable; CVA/TIA: Cerebro Vascular Accident/Transient Ischemic Attack. 
Table 3. Eventual predictive factors of high BMI in RA patients.

\begin{tabular}{cccc}
\hline & OR & $95 \%$ CI & $\mathrm{p}^{*}$ \\
\hline MTX & 1.24 & $0.31-4.96$ & 0.76 \\
HCQ & 0.56 & $0.07-4.74$ & 0.59 \\
Corticosteroids & 1.22 & $0.28-5.21$ & 0.79 \\
Age & 1.52 & $0.23-10.2$ & 0.67 \\
Male sex & 5.13 & $0.54-0,52$ & 0.15 \\
Sedentarity & 4.9 & $48.33-45.98$ & 0.16 \\
\hline
\end{tabular}

OR: Odds Ratio; 95\% CI: 95\% Confidence Interval; p*: p-value; MTX: Methotrexate; HCQ: Hydroxychloroquine.

Table 4. Predictive factors of abdominal obesity in RA patients.

\begin{tabular}{cccc}
\hline & OR & $95 \%$ CI & $\mathrm{p}^{*}$ \\
MTX & 1.31 & $0.31-1.69$ & 0.71 \\
HCQ & 1.47 & $0.12-2.92$ & 0.76 \\
Corticosteroids & 1.27 & $0.28-1.75$ & 0.29 \\
Age & 3.56 & $0.33-38.34$ & 0.011 \\
Male Sex & 0.02 & $0-0.73$ & 0.09 \\
Sedentarity & 7.14 & $0.4-69.39$ & 0.09
\end{tabular}

OR: Odds Ratio; 95\% CI: 95\% Confidence Interval; p*: p-value; MTX: Methotrexate; HCQ: Hydroxychloroquine.

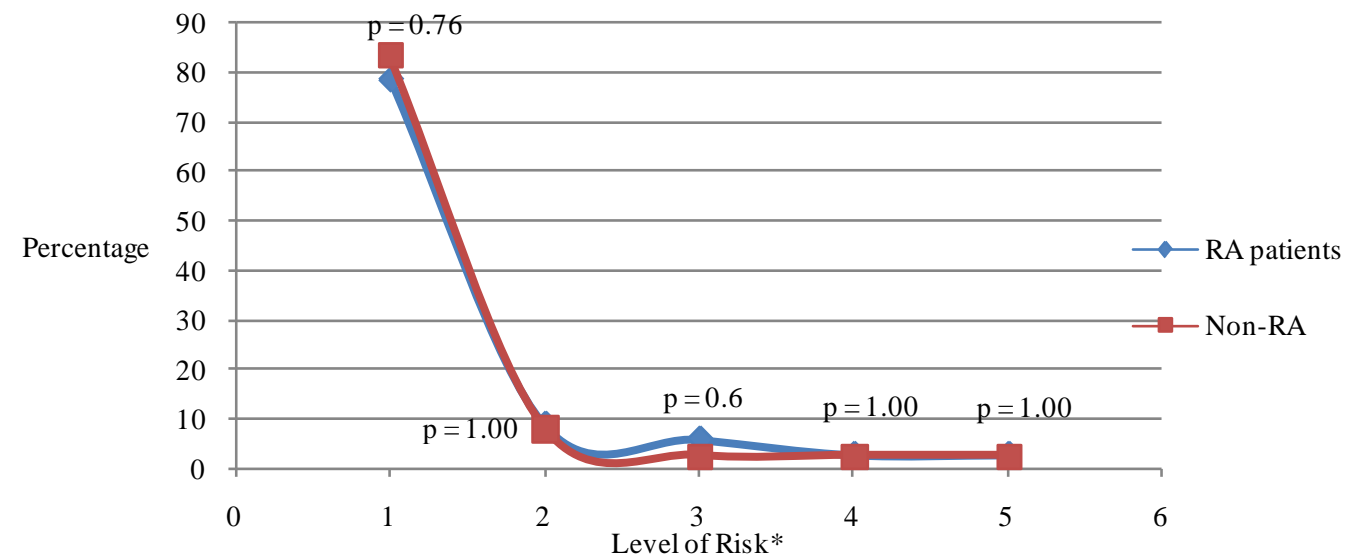

Figure 1. Cardiovascular risks of the study population; 1 : $<10 \%$; $2: 10 \%$ to $<20 \%$; $3: 20 \%$ to $<30 \%$; 4 : $30 \%$ to $<40 \%$; $5: \geq 40 \%$; *Risk estimated for 33 RA patients and 36 non-RA subjects.

the development of cardiovascular risk factors such as overweight and obesity [28]. We noted that increasing BMI weakly correlated with the duration of RA, independently of treatments of RA, age, sex, sedentarity and disease-specific treatments. Similar findings have been reported in a Moroccan study [29], and contrasts with that of the general population [30] [31]. However, it is possible that structural damages due to X-rays, rheumatoid factor, anti-CCP anti-bodies, and DAS 28 could also correlate with BMI values along with disease duration in these patients [29]. Furthermore, more than half of the RA patients had abdominal obesity. Female sex seemed to be a risk factor. Surprisingly [29], abdominal obesity occurred independently to treatments of RA, age, and physical inactivity. This suggests the possible interaction of both factors inherent to RA patients and RAspecific factors. 
Sedentarity was significantly noted in $20 \%$ of RA patients $(\mathrm{p}=0.001)$. Desse in et al. have also reported substantial reduction in weekly physical activities in South African Black RA patients [27]. Remarkably, patients present late with invalidating polyarthralgia in our settings [32] [33].

RA patients had a low cardiovascular risk, similarly to their non-RA counterparts. This low cardiovascular risk in RA patients based on general population calculators has already been reported by Crows on et al. [34]. Indeed, RA patients from their cohort had a low cardiovascular risk as calculated by the Framingham equation at baseline, contrasting with an increased cardiovascular risk eight years later at the end of the study. Similarly, Gomez-Vaquero et al. have reported a low cardiovascular risk in Spanish RA patients when using the SCORE (Systematic Coronary Risk Evaluation) and REGICOR (Framingham-Register GIRONI del COR) estimation methods [35].

Only markers of adiposity and prevalence of physical inactivity differed between RA patients and non-RA subjects. In the general population, excess adiposity reflected by high BMI and abdominal obesity were shown to be predictors of high cardiovascular mortality [30]. This linear relationship has not been fully elucidated in black Africans with RA [17]. Our findings, comparable with previous studies [17], present the later as obese RA subjects without necessarily having high cardiovascular risk. With respect to the literature, there is a link between overproduction of adipokines and alteration of cardiovascular risk in obese subjects. In black RA patients, Salmon et al. have reported some adipokines to be correlated with markers of atherosclerosis [17].

It is thus possible that cardiovascular risk in obese Black RA subjects is rather linked to adipokines but not to BMI, corollary to abdominal obesity that seems to be linked to endothelial activation, the initial step of atherosclerosis [17]. In this light, we can speculate that the WHO risk charts underestimated the cardiovascular risk in this population of patients with RA population, as was previously described with other evaluation tools of cardiovascular risk in the general population [18] [34]-[40]. This hypothesis could be verified in future studies where the cardiovascular risks will be estimated using the WHO risk charts and simultaneously compared to measured clinical markers of atherosclerosis (Carotid plaques, intima-media thickness of the carotid arteries). Meanwhile, methods for evaluation of the cardiovascular risks specific to Black Africans recently proposed by Solomon et al. [17] [18] could be more useful. They include the systematic Doppler ultrasound of the carotid arteries, use of biomarkers such as adipokines, intereukin- 6 and kidney disease markers. These biomarkers could therefore be evaluated in subsequent prospective studies including Black RA patients, in view of incorporating these in specific risk equations, before making strong recommendations for their systematic use in Africans or Afro-Americans with RA populations. As an alternative, more accessible and validated biomarkers in Caucasian cohorts with RA like apolipoprotein-A1 could be measured [40]. However, risk equations specific to RA under development such as ATACC-RA, will permit in better classifying patients following an adapted stratum during follow up visits of RA in the near future [36].

This research has many drawbacks that could jeopardize definite conclusions. The small sample size and the cross-sectional nature do not allow us to make inferences of causality, nor to generalize the results. Lack of auto antibody study in the non-RA group could be a source of selection bias. The prevalence of past history of cardiovascular events could be wrongly estimated due to recall bias, despite the use of consecrated questionnaire for public use by WHO [23]. Still, we did not study the correlation between BMI and activity indices, Sharp score, and inflammatory markers, to completely elucidate the association between RA and high BMI. Beyond all those limits, findinds of this study are strengthened by the fact that most patients with established RA in Yaounde and its environs have likely been included in the study considering the rheumatology unit of the Yaounde Central Hospital as the lone rheumatology unit which centralizes the majority of RA patients from Yaounde. Besides, the non-RA subjects issued from the community were rigorously selected excluding all possible potential confounders. These contributed to data reliability.

\section{Conclusion}

Despite the excess adiposity burden and the high prevalence of sedentarity in RA patients, RA was not associated with cardiovascular risk as estimated by WHO risk charts. Prospective studies should be carried out on larger samples, so as to attain two main objectives: first of all, to evaluate the reliability of WHO cardiovascular risk predicting charts as against measured markers of atherosclerosis; then, to evaluate the relationship between specific markers and atherosclerosis, abdominal obesity and the different stages of atherosclerosis in RA patients. Along with this, we would better predict cardiovascular risk in Black African RA patients in the future. 


\section{References}

[1] Cross, M., Smith, E., Hoy, D., et al. (2014) The Global Burden of Rheumatoid Arthritis: Estimates form the Global Burden of Disease 2010 Study. Annals of the Rheumatic Diseases, 73, 1316-1322. http://dx.doi.org/10.1136/annrheumdis-2013-204627

[2] Dowman, B., Campbell, R.M., Zgaga, L., et al. (2012) Estimating the Burden of Rheumatoid Arthritis in Africa: A Systematic Analysis. Journal of Global Health, 2, Article ID: 020406. http://dx.doi.org/10.7189/jogh.02.020406

[3] Dadoun, S., Zeboulon-Ktorza, N., Combescure, C., et al. (2013) Mortality in Rheumatoid Arthritis over the Last Fifty Years: Systematic Review and Meta-Analysis. Joint Bone Spine, 80, 29-33. http://dx.doi.org/10.1016/j.jbspin.2012.02.005

[4] Dougados, M., Soubrier, M., Antunez, A., et al. (2014) Prevalence of Comorbidities in Rheumatoid Arthritis and Evaluation of Their Monitoring: Results of an International, Cross-Sectional Study (COMORA). Annals of the Rheumatic Diseases, 73, 62-68. http://dx.doi.org/10.1136/annrheumdis-2013-204223

[5] Lévy, L., Fautrel, B., Barnetche, T. and Schaeverbeke, T. (2008) Incidence and Risk of Fatal Myocardial Infarction and Stroke Events in Rheumatoid Arthritis Patients. A Systematic Review of the Literature. Clinical and Experimental Rheumatology, 26, 673-679.

[6] Aviña-Zubieta, J.A., Choi, H.K., Sadatsafavi, M., et al. (2008) Risk of Cardiovascular Mortality in Patients with Rheumatoid Arthritis: A Meta-Analysis of Observational Studies. Arthritis \& Rheumatology, 59, 1690-1697. http://dx.doi.org/10.1002/art.24092

[7] Meune, C., Touzé, E., Trinquart, L., et al. (2009) Trends in Cardiovascular Mortality in Patients with Rheumatoid Arthritis over 50 Years: A Systematic Review and Meta-Analysis of Cohort Studies. Rheumatology (Oxford England), 48, 1309-1313. http://dx.doi.org/10.1093/rheumatology/kep252

[8] Meune, C., Touzé, E., Trinquart, L., et al. (2010) High Risk of Clinical Cardiovascular Events in Rheumatoid Arthritis: Levels of Associations of Myocardial Infarction and Stroke through a Systematic Review and Meta-Analysis. Archives of Cardiovascular Diseases, 103, 253-261. http://dx.doi.org/10.1016/j.acvd.2010.03.007

[9] Aviña-Zubieta, J.A., Thomas, J.A., Sadatsafavi, M., et al. (2012) Risk of Incident Cardiovascular Events in Patients with Rheumatoid Arthritis: A Meta-Analysis of Observational Studies. Annals of the Rheumatic Diseases, 71, 15241529. http://dx.doi.org/10.1136/annrheumdis-2011-200726

[10] Aslam, F., Bandeali, S.J., Khan, N.A., et al. (2013) Diastolic Dysfunction in Rheumatoid Arthritis: A Meta-Analysis and Systematic Review. Arthritis Care \& Research, 65, 534-543. http://dx.doi.org/10.1002/acr.21861

[11] Corrao, S., Messina, S., Pistone, G., et al. (2013) Heart Involvement in Rheumatoid Arthritis: Systematic Review and Meta-Analysis. International Journal of Cardiology, 167, 2031-2038. http://dx.doi.org/10.1016/j.ijcard.2012.05.057

[12] Boyer, J.-F., Gourand, P.A., Cantagrel, A., Davignon, J.-L. and Constantin, A. (2011) Traditional Cardiovascular Risk Factors in Rheumatoid Arthritis: A Meta-Analysis. Joint Bone Spine, 78, 179-183. http://dx.doi.org/10.1016/j.jbspin.2010.07.016

[13] Baghdadi, I.R., Woodman, R.J., Shanaban, E.M. and Mangoni, A.A. (2015) The Impact of Traditional Cardiovascular Risk Factors on Cardiovascular Outcomes in Patients with Rheumatoid Arthritis: A Systemic Review and Meta- Analysis. PloS One, 10, e117952. http://dx.doi.org/10.1371/journal.pone.0117952

[14] Barber, C.E.H., Smith, A., Esdaile, J.M., Barnabe, C., Martin, L.O., Faris, P., et al. (2015) Best Practices for Cardiovascular Disease Prevention in Rheumatoid Arthritis: A Systematic Review of Guideline Recommendations and Quality Indicators. Arthritis Care \& Research, 67, 169-179. http://dx.doi.org/10.1002/acr.22419

[15] Essouma, M. and Noubiap, J.J.N. (2015) Therapeutic Potential of Folic Acid Supplementation for Cardiovascular Diseases Prevention through Homocystein Lowering and Blockade in Rheumatoid Arthritis Patients. Biomarker Research, 3, 24. http://dx.doi.org/10.1186/s40364-015-0049-9

[16] Kirui, F., Oyoo, G.O. and Amayo, E.O. (2013) Cardiovascular Risk Factors in Patients with Rheumatoid Arthritis at Kenyatta National Hospital. African Journal of Rheumatology, 1, 15-22.

[17] Solomon, A., Tsang, L., Woodiwiss, A.J., et al. (2014) Cardiovascular Disease Risk amongst African Black Patients with Rheumatoid Arthritis: The Need for Population Specific Stratification. BioMed Research International, 2014, Article ID: 826095, 10 p.

[18] Dessein, P.H., Hon-Chun, H., Tsang, L., et al. (2015) Kidney Function, Endothelial Activation and Atherosclerosis in Black and White Africans with Rheumatoid Arthritis. PLoS One, 10, e0121693. http://dx.doi.org/10.1371/journal.pone.0121693

[19] Aletaha, D., Neogi, T., Silman, A.J., et al. (2010) Rheumatoid Arthritis Classification Criteria: An American College of Rheumatology/European League against Rheumatism Collaborative Initiative. Arthritis \& Rheumatology, 62, 25692581. http://dx.doi.org/10.1002/art.27584 
[20] Arnett, F.C., Edworthy, S.M., Bloch, D.A., et al. (1988) The American Rheumatism Association 1987 Revised Criteria for the Classification of Rheumatoid Arthritis. Arthritisrheum, 31, 315-324. http://dx.doi.org/10.1002/art.1780310302

[21] Tensiomètre Médical Brassard Magnien B1, 2012 (2014). http://www.powersante.com/sante/materiel-medical-accessoires/tensiomètres-automatiques/magnien-tensiometre-medi cal-brassard-b1-magnien.html.

[22] Whitworth, J.A., World Health Organization, International Society of Hypertension Writing Group (2003) World Health Organization (WHO)/International Society of Hypertension (ISH) Statement on Management of Hypertension. Journal of Hypertension, 21, 1983-1992. http://dx.doi.org/10.1097/00004872-200311000-00002

[23] World Health Organization (2006) Comment éviter une crise cardiaque ou un accident vasculaire cérébral. http://www.who.int/publications/list/9241546727/fr

[24] World Health Organization (2007) Prévention des maladies cardiovasculaires. www.who.int/entity/cardiovascular_diseases/publications/cardio_pocket_guidelines/fr

[25] Alberti, K.G.M.M. and Zimmet, P.Z. (1998) Definition, Diagnosis and Classification of Diabetes Mellitus and Its Complications, Part 1: Diagnosis and Classification of Diabetes Mellitus: Provisional Report of a WHO Consultation. Diabetic Medicine, 15, 539-553. http://dx.doi.org/10.1002/(SICI)1096-9136(199807)15:7<539::AID-DIA668>3.0.CO;2-S

[26] Lombard, A., du Plessis, M. and Visser, J. (2014) Body Composition of Rheumatoid Arthritis Patients in the City of Cape Town, South Africa. Clinical Rheumatology, 33, 467-476. http://dx.doi.org/10.1007/s10067-013-2414-0

[27] Dessein, P.H., Woodiwiss, A.J., Norton, G.R., et al. (2013) Rheumatoid Arthritis Is Associated with Reduced Adiposity but Not with Unfavorable Major Cardiovascular Risk Factor Profiles and Enhanced Atherosclerosis in Black Africans from a Developing Population: A Cross Sectional Study. Arthritis Research \& Therapy, 15, R96. http://dx.doi.org/10.1186/ar4276

[28] Faam, B., Zarkesh, M., Daeshpour, M.S., et al. (2014) The Association between Inflammatory Markers and ObesityRelated Factors in Tehranian Adults: Tehran Lipid and Glucose Study. Iranian Journal of Basic Medical Sciences, 15, 577-582.

[29] Yacoub, Y.I., Amine, B., Laatiris, A., et al. (2012) Prevalence of Overweight in Moroccan Patients with Rheumatoid Arthritis and Its Relationships with Disease Features. Clinical Rheumatology, 31, 479-482. http://dx.doi.org/10.1007/s10067-011-1874-3

[30] Perk, J., De Backer, G., Gohlke, H., et al. (2012) European Guidelines on Cardiovascular Disease Prevention in Clinical Practice (Version 2012): The Fifth Joint Task Force of the European Society of Cardiology and Other Societies on Cardiovascular Disease Prevention in Clinical Practice (Constituted by Representatives of Nine Societies and by Invited Experts). European Heart Journal, 33, 1635-1701. http://dx.doi.org/10.1093/eurheartj/ehs092

[31] Abondo, O., Moute, C., Moodjom, R.M., et al. (2014) La surcharge pondérale féminine au Cameroun Evolution de 2004 à 2011. Medecine Afrique Noire, 61, 358-367.

[32] Elkan, A.-C., Engvall, I.-L., Cederholm, T. and Hafström, I. (2009) Rheumatoid Cachexia, Central Obesity and Malnutrition in Patients with Low-Active Rheumatoid Arthritis: Feasibility of Anthropometry, Mini Nutritional Assessment and Body Composition Techniques. European Journal of Nutrition, 48, 315-322. http://dx.doi.org/10.1007/s00394-009-0017-y

[33] Ndongo, S., Leckpa, F.K., Ka, M.M., et al. (2009) Presentation and Severity of Rheumatoid Arthritis at Diagnosis in Senegal. Rheumatology, 48, 1111-1113. http://dx.doi.org/10.1093/rheumatology/kep178

[34] Crowson, C.S., Matteson, E.L., Roger, V.L., et al. (2012) Usefulness of Risk Scores to Estimate the Risk of Cardiovascular Disease in Patients with Rheumatoid Arthritis. American Journal of Cardiology, 110, 420-424. http://dx.doi.org/10.1016/j.amjcard.2012.03.044

[35] Gomez-Vaquero, C., Corrales, A., Zacarias, A., et al. (2013) SCORE and REGICOR Function Charts Underestimate the Cardiovascular Risk in Spanish Patients with Rheumatoid Arthritis. Arthritis Research \& Therapy, 15, R91. http://dx.doi.org/10.1186/ar4271

[36] Peters, M.J.L., Symmons, D.P.M., McCarey, D., et al. (2010) EULAR Evidence-Based Recommendations for Cardiovascular Risk Management in Patients with Rheumatoid Arthritis and Other Forms of Inflammatory Arthritis. Annals of the Rheumatic Diseases, 69, 325-331. http://dx.doi.org/10.1136/ard.2009.113696

[37] Semb, A.G., Rollefstadt, A.G., Riel, P.V., et al. (2014) Cardiovascular Disease Assessment in Rheumatoid Arthritis: A Guide to Translating Knowledge of Cardiovascular Risk into Clinical Practice. Annals of the Rheumatic Diseases, 73, 1284-1288. http://dx.doi.org/10.1136/annrheumdis-2013-204792

[38] Martin-Martinez, M.A., Gonzalez-Juanatey, C., Castaneda, S., et al. (2014) Recommendations for the Management of Cardiovascular Risk in Patients with Rheumatoid Arthritis: Scientific Evidence and Expert Opinion. Seminars in Arthritis and Rheumatism, 44, 1-8. http://dx.doi.org/10.1016/j.semarthrit.2014.01.002 
[39] Soubrier, M., Barber-Chamoux, N., Tatar, Z., et al. (2014) Risque cardiovasculaire de la polyarthrite rhumatoïde. Revue du Rhumatisme, 81, 281-285. http://dx.doi.org/10.1016/j.rhum.2013.12.017

[40] Finckh, A., Courvoisier, D.S., Pagano, S., et al. (2012) Evaluation of Cardiovascular Risk in Patients with Rheumatoid Arthritis: Do Cardiovascular Biomarkers Offer Added Predictive Ability over Established Clinical Risk Scores? Arthritis Care \& Research, 64, 817-825. http://dx.doi.org/10.1002/acr.21631 